\title{
Clóvis Ultramari
}

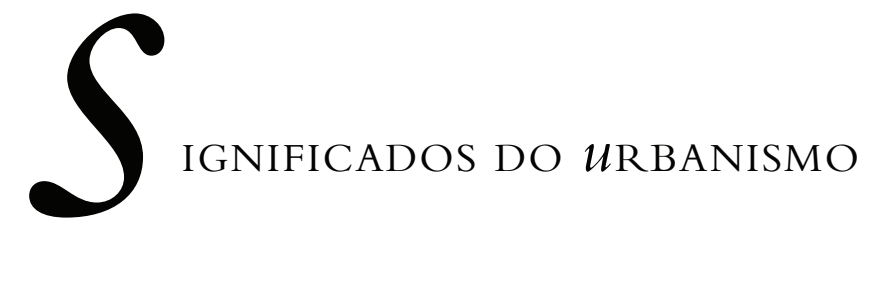

\section{RESUMO}

O que se apresenta neste artigo é uma busca, ainda não finalizada, dos significados possíveis de observar-se em relação ao urbanismo. Para tanto, discutem-se também suas relações com o planejamento urbano e o desenho urbano. Ressalta as similaridades e diferenças entre esses conceitos e o fato de serem, muitas vezes, usados indistintamente. 0 artigo é construído a partir de duas hipóteses: a de uma maior abrangência da atuação do urbanismo, o qual incorporaria o planejamento urbano, e a de a distinção conceitual dessas duas ciências (ou práticas?) poderem ser feitas a partir de uma maior ou menor aproximação da arte e da arquitetura. Quanto maior a aproximação, mais próximo da faceta de intervenção física do urbanismo estamos; quanto mais distantes, mais claro fica 0 conceito de planejamento urbano. 0 artigo tem caráter provocativo e está consciente da polêmica que pode gerar, sendo esse seu objetivo principal. A discussão aqui relatada tem como base uma pesquisa na literatura e em discussões com colegas pesquisadores e alunos. Estrutura-se com uma introdução que ressalta a dificuldade de uma discussão epistemológica e partes em que se estabelecem semelhanças e distinções dos conceitos tratados e uma conclusão que, sem se resguardar de um posicionamento, propõe a continuidade da discussão.

\section{Palavras-Chave}

Planejamento urbano, gestão urbana, desenho urbano, urbanismo. 


\section{SigNIFICADOS DEL URBANISMO}

\section{RESUMEN}

Lo que se presenta en el artículo es una búsqueda todavía inacabada de los significados posibles de se encontrar para Urbanismo. Para eso, se discute también sus relaciones con la Planificación Urbana y el Diseño Urbano, las similitudes y diferencias entre estos conceptos y el hecho de que muchas veces son utilizados indistintamente. El artículo se construye a partir de dos hipótesis: una que supone una actuación más amplia del Urbanismo, el que incorporaría la Planificación Urbana; y la que afirma que la distinción conceptual de esas dos ciencias (¿o prácticas?) se puede hacer a partir del grado de acercamiento del Arte y de la Arquitectura. Cuanto más cercano, más nos aproximamos de la faceta de intervención física del Urbanismo; cuanto más lejano, más claro queda el concepto de Planificación Urbana. El artículo tiene carácter provocativo y conciencia de la controversia que puede generar, lo que es su objetivo principal. La discusión presentada aquí tiene como base una investigación en la literatura y debates con compañeros investigadores y alumnos. Él se estructura con una introducción que da énfasis a la dificultad de un debate epistemológico, partes donde se establecen semejanzas y distinciones de los conceptos discutidos, y una conclusión que, no obstante presente una posición, propone también la continuidad del debate.

\section{Palabras Clave}

Planificación urbana, gestión urbana, diseño urbano, urbanismo. 


\section{THE MEANING OF URBANISM}

\section{ABSTRACT}

This article discusses an incomplete search on the different meanings understood from urbanism. It does so by discussing the relation of urbanism with urban planning and urban design. The similarities and differences between these concepts and the fact that they are often used indistinctly are pointed out. The current article is organized around two hypotheses, where the first involves a broader understanding of urbanism, which incorporates urban planning, and the second is based on the idea that the conceptual distinction between these two fields may be defined according to how close or how far urbanism is from art and architecture. The closer urbanism is to art and architecture, the more it moves away from urban planning. The ideas presented here are intended to be provocative, and the author is aware of reactions they may generate. This discussion is based on a technical literature as well as on debates with other researchers and students. The article starts with an introduction regarding the difficulties and complexities of an epistemological discussion while later sections point out similarities and distinctions between the two main concepts. The conclusion makes the author's position clear, but suggests that this issue needs further discussion.

\section{KEY WORDS}

Urban planning, urban management, urban design, urbanism. 


\section{O PROPÓSITO DESTE ARTIGO}

Este artigo apresenta uma reflexão sobre urbanismo e planejamento urbano em termos de áreas de conhecimento cujo objeto é a realidade urbana, e, também, por extensão natural, o da região que a contém. Para essa abordagem, além dos dois principais conceitos que se busca discutir, obrigatoriamente, são acrescentados os de desenho urbano e, de forma subentendida, o de gestão urbana. Na discussão aqui apresentada buscam-se similaridades e diferenças entre esses conceitos, como eles são entendidos e como abordam o fenômeno urbano. Estruturado de forma inegavelmente pretensiosa, como um ensaio epistemológico, este artigo busca reconhecer o trajeto conceitual e operacional do urbanismo e do planejamento urbano, algumas vezes, de fato, utilizados de modo indistinto, a partir do momento em que aparecem como possíveis ciências da cidade.

O objetivo do artigo é tão-somente o de responder a preocupações conceituais que surgem entre os que planejam, administram ou pesquisam a cidade. No cotidiano dessas tarefas, observa-se, pois, pouca clareza entre o significado de urbanismo, de planejamento urbano, de desenho urbano e de gestão urbana. Não se reproduz, aqui, estudos já anteriormente realizados os quais, em uma revisão histórica, resgatam as diferentes fases do urbanismo e mesmo do planejamento urbano. A despeito do fato de esses trabalhos contribuirem grandemente para o esclarecimento dos conceitos discutidos, optou-se por priorizar a discussão mais propriamente epistemológica.

A elaboração deste artigo iniciou com a certeza que urbanismo, seja como ciência, seja como área de conhecimento, estaria fortemente ligado à idéia de intervenção física no espaço das cidades, alterando-as ou construindo-as com propostas e obras de embelezamento, saneamento, sistema viário, espaços públicos e privados. Em alguns momentos da discussão, este autor se viu obrigado a reconhecer que existem outros entendimentos de urbanismo, avançando para uma direção que parece estar mais próxima do conceito de planejamento urbano, sobretudo quando sua preocupação é organizar a maneira como a própria sociedade constrói e consome a cidade. Tal dubiedade, evidentemente, é reduzida se observarmos os conceitos de forma isolada. Professor Bernardo Secchi (2005), por exemplo, ainda que com postura relativista, evidencia, em seu conceito de urbanismo, a existência ou a busca de transformações físicas:

"Portanto, por Urbanismo entendo não tanto um conjunto de obras, de projetos, de teorias ou normas associadas a um tema, a uma linguagem e a uma organização discursiva; muito menos o entendo como um determinado setor do ensino, mas ao contrário como um testemunho de um vasto conjunto de práticas, quais sejam as da contínua e consciente modificação do estado do território e da cidade." 
Leme (1999) contribui para esclarecer essa questão ao resumir o percurso histórico do urbanismo no Brasil: primeiramente, um domínio de "pioneiros", seguidos de engenheiros-arquitetos, arquitetos e, finalmente, equipes multidisciplinares. Essa mesma síntese é reiterada na identificação, pela autora, dos períodos do urbanismo brasileiro:

"É importante destacar que durante esse período, do final do século XIX aos anos 60, foram se configurando duas linhas de Urbanismo: uma que se iniciou nos planos de melhoramentos que, em seguida, se ampliaram para o conjunto da área urbana, para a aglomeração e receberam a denominação, já na década de 70, de Planos Diretores de Desenvolvimento Integrado." (LEME, 1999)

A mudança de entendimentos que se vivenciou na elaboração deste artigo resulta, talvez, da lembrança de o urbanismo, quando se quis modernista, por exemplo, como sabemos, não ter se apresentado apenas como um projeto de intervenção física em uma cidade específica. Ao contrário, o movimento chamado urbanismo modernista se caracteriza como um corolário, um manual mesmo, de como proceder para se chegar à cidade ideal. Com isso o urbanismo, utopicamente, acreditava poder alterar a cidade enquanto espaço construído e também a sociedade que a constrói e usa-a. De fato, esse urbanismo - e essa é a palavra utilizada ao invés de planejamento urbano, não apenas desenha a cidade que se quer, mas também determina como essa deve ser obtida e usada, ou seja, acreditando na utopia de poder formatar a sociedade que aí habita. Todavia, ao se considerar o antagonismo entre o acreditar em mudanças societárias a partir do desenho do assentamento urbano proposto e o pensar essas mudanças por meio de novas relações entre seus componentes sociais, o artigo volta a diferenciar os conceitos aqui tratados tal qual em seu início.

A inserção, portanto, de questões relativas às relações da sociedade ao desenho proposta para a cidade parece aproximar o conceito de urbanismo ao de planejamento urbano.

"A busca da superação dos problemas sociais era procurada através da apresentação de novas formas urbanas. Tencionava-se criar uma cidade melhor a partir da fé na técnica e progresso. Porém, isso mostrou-se uma falácia que Brasília e suas cidades satélites exemplificam de maneira transparente. A exclusão social não pode ser resolvida através do incremento de técnicas modernas na construção, ou ser equalizada tão-somente via planejamento pelo Estado." (DIAS, 2000)

Tão-somente a partir da exposição acima observa-se uma dificuldade em distinguir os três termos aqui discutidos. Desse modo, algumas perguntas estão na base dessa discussão sobre eles. Seriam esses termos: urbanismo, planejamento urbano e, a partir de uma relação imediata, desenho urbano - uma evolução histórica de uma mesma idéia ou convivem no mesmo tempo? São conceitos contraditórios ou complementares? Finalmente, tratam do mesmo objeto?

Para iniciar esse debate, diferencia-se o ato de fazer de seu ato anterior, o de planejar. Em um primeiro momento, tem-se o planejamento urbano como ato de planejar, o qual explicita a cidade que se quer em um plano, não necessariamente de forma gráfica. São exemplos o plano diretor municipal e mesmo uma lei de uso e ocupação do solo, os quais explicitam desejos e normas a serem implementados por outrem, ao longo de momentos futuros. Em um segundo 
momento, o urbanismo, o ato de intervir fisicamente, de construir, de ampliar, de reciclar, ou de revitalizar, a partir de um projeto gráfico e intencionalmente claro. Paralelamente a essas duas ações tem-se a gestão ou administração urbana, capaz e responsável para optar pelo momento de planejar-se ou de intervir-se, ou seja, de fazer-se planejamento ou urbanismo. Cabe a essa gestão também a responsabilidade de executar o desejado no plano e de manter o que foi implantado.

Ao se adotar esse entendimento, ter-se-ia o planejamento urbano vinculado ao entendimento mais tradicional da cidade, ou seja, aquele que a planeja, que define como deverá ser seu futuro, quais os caminhos a seguir, as prioridades a adotar, os espaços a ocupar e a não ocupar, as obras a serem realizadas. Uma vez finalizado esse planejamento, cabe à gestão o papel de executá-lo e fiscalizá-lo. De outra forma, o urbanismo estaria mais vinculado à técnica da engenharia e da arquitetura para a implementação daquilo que é físico (a obra) e anteriormente determinado pelo planejamento (o plano). Se, no caso do planejamento urbano, a equipe de profissionais requerida é multidisciplinar, no caso do urbanismo valoriza-se a função do arquiteto urbanista por excelência, apoiado por profissionais das diversas engenharias.

Tal simplificação não deve, entretanto, justificar o encerramento da discussão sobre a forma mais correta de utilizar-se esses conceitos. Ao contrário, tal distinção linear deve instigar a dúvida. Contudo, considerando a carência de referências com as quais se conta para se discutir epistemologicamente esses conceitos, a contribuição deste artigo está em provocar a discussão. Com isso, ressalta-se a importância de uma revisão epistemológica do planejamento e do urbanismo entre nós, procedendo, inclusive, relações com os termos usados por academias estrangeiras que se servem de outras línguas na discussão da cidade.

Para a presente discussão, o texto é dividido, além dessa introdução, em cinco partes. A primeira apresenta uma abordagem de qual é, afinal, nosso objeto. Para isso é apresentada uma discussão sobre os termos cidade e urbano, com base em Henri Lefebvre. Tais termos, sempre presentes em discussões como a deste artigo, têm, de fato, significados científicos muito próximos, porém com diferenças sutis que podem facilitar a distinção conceitual aqui procurada.

A cidade como objeto e o urbano como fenômeno foi uma distinção conceitual proposta por Henri Lefebvre já nos anos 60. Para ele, o urbano é o conjunto de forças culturais, sociais e econômicas, cuja expressão física, responsável, inclusive, para a reprodução desse fenômeno, era a cidade. Essa distinção, puramente conceitual, é uma forma de tornar claros dois termos usados, por vezes, como sinônimos. A cidade seria, nesses termos, o lócus de fluxos financeiros, relações sociais, políticas, econômicas, e onde ocorre a concentração de bens de reprodução do capital e da mão-de-obra e o lócus ideal, pela convergência dessas forças, para sua reprodução e disseminação. Se assim entendidos, cidade e urbano seriam, nessa seqüência, os objetos de trabalho do planejamento urbano (por extensão, o regional também) e do urbanismo. Para uma sociedade que se urbaniza nos ecúmenos do território e também nas complexas relações sociais, exige do planejamento urbano até mesmo sua revisão, pois amplia seus espaços de atuação de forma quase global. Tomando como exemplo o caso do plano diretor, para o caso específico brasileiro: a ciência que o elabora, o planejamento urbano agora não parece mais ser suficiente. Ao se ampliar, 
constitucionalmente, a responsabilidade desses planos para além do traçado do perímetro urbano até os limites político-administrativos do município, distanciar-seia do detalhe do urbanismo e mesmo do tradicional planejamento urbano ${ }^{1}$, mas avançar-se-ia para um desejo, mais uma vez, de consertar a sociedade.

\section{DO URBANISMO AO PLANEJAMENTO URBANO?}

(1) 0 plano diretor, tal qual concebido pela Constituição de 1988 se obriga, agora, a considerar todo o território do município e não mais os limites do perímetro urbano.

(2) Se traduzido por Organização do território, estaria mais próximo do conceito de planejamento urbano e regional. Preocupado com o desenvolvimento econômico e as desigualdades entre espaços, o Aménagement du territoire, tal qual o planejamento urbano e regional, fundamentamse, prioritariamente, em leis e planos, ao contrário de desenhos ou projetos de intervenções físicas.
A partir da consolidação de um processo histórico e mesmo civilizatório de urbanização ocorrida nos finais do século 19 , com a assimilação pela sociedade da Revolução Industrial, seria obrigatória a busca de soluções para problemas criados por um novo uso sobre um espaço antigo e sobre espaços naturais de, forma jamais vista. Esse fenômeno socioeconômico acontecendo sobre uma base física chamada cidade requereria, então, novos procedimentos de análise e de intervenção científica, oportunizando a formalização da ciência do urbanismo.

Pertencem a esse período experiências marcantes na história da cidade, algumas delas ainda desprovidas do necessário conhecimento do fenômeno urbano e, sobretudo, de suas características sociais, econômicas, políticas e ambientais. Na tentativa de encontrar-se a cidade ideal ou mesmo a cidade utópica, fazendo referência àquilo que quase 500 anos antes Thomas Morus havia idealizado, tornaram-se conhecidos os exemplos de Fourier, com o Falanstério; de Ebenezer Howard, com a Cidade-jardim; e de Tony Garnier com a Teoria da cidade industrial, dentre inúmeros outros.

Se tais propostas vivenciaram um desencanto em termos de implementação e de continuidade de suas propostas, permitiram gerar uma diversidade de conhecimentos na busca de soluções, principalmente referentes à relação moradia-trabalho, para os então chamados problemas urbanos. Segundo Françoise Choay, a elaboração dessas propostas ainda carece de um melhor entendimento de como se dava a emergente produção industrial e a recente organização de novos grupos sociais. Para o que mais nos interessa neste artigo, as iniciativas nesse período, ainda que preocupados em enfrentar novos problemas de uma nova sociedade, exemplificam um urbanismo sempre explicitado pelo desenho, pela forma da cidade desejada. O Urbanisme, conforme nomeado por Choay, poderia até ser confundido com planejamento urbano, ou mesmo com Aménagement du territoire ${ }^{2}$, porém fica aqui evidente, nesses exemplos, o traço do arquiteto urbanista e a cidade ideal sintetizada em desenho.

Nesse momento, de gênese do urbanismo, a cidade ainda era vista como um objeto de interesse pontual e marginal em outras ciências, chamando a atenção de seus aspectos quantitativos - seu volume demográfico e o porquê de seu crescimento - para uma sociologia urbana que começava a consolidar-se. Do mesmo modo, a cidade se mostrava como objeto de estudo para as ciências mais preocupadas com os aspectos higienistas e sanitaristas, muito em resposta a um problema ostensivo que resultara de uma urbanização acelerada, pouco planejada e com índices de qualidade de vida bastante baixos.

A partir desse momento, a cidade é claramente o lócus central de relações econômicas, de fluxos, de interesses, riqueza e pobreza, de enriquecer, servir e trabalhar, abolindo, gradualmente, uma relação simplista de oposição do espaço construído e do espaço natural ou rural. Tal cenário, mais especificamente o da 
(3) Pode-se, talvez, localizar essa fase de enaltecimento da vida urbana no final do século 19 , conforme sugerido nas descrições de Christophe Charle, em Paris fin-desiècle, ou de Richard Sennet, em O declínio do homem público, os quais descrevem as transformações das obras de Barão de Haussmann, e Viena fin-de-sciècle: Política e cultura, de E. Schorske (1988), o qual descreve com relevância as obras de reforma para a construção da Ringstrassen nesse período. Desnecessário dizer aqui que ta enaltecimento é também acompanhado de críticas e desconfianças

(4) Para melhor compreensão dessas idéias, vide discussões sobre iniciativas urbanísticas de Frank Lloyd Wright o qual, no início do século 20, propõe sua Broadacre City, uma inverossímil mescla de cidade e de campo; e a obra de Lewis Munford, A cidade na história: Suas origens, transformações e perspectivas. $4^{a}$ ed. São Paulo: Martins Fontes, 1998. Nessa obra, ressalta-se o capítulo final, em que o autor critica a grande metrópole contemporânea. habitação das classes trabalhadoras em Londres, sugere à teoria marxista um entendimento evidentemente abrangente, abordando questões sobre a economia, a sociedade e os impactos dos interesses do capital na utilização do solo urbano. A partir desse período, o qual evidencia um novo processo de densificação dos assentamentos humanos, a predominância do fenômeno urbano sobre qualquer outra manifestação socioeconômica territorial é crescente. A consolidação desse processo justificaria a perspectiva de urbanização total adotada por Lefebvre, o que não significa uma cidade (objeto concreto) de extensão global, e sim um fenômeno urbano global.

A ciência do urbanismo, sugerida por um fenômeno novo, a cidade, assim se configura formalmente a partir de um problema: o de um espaço com fatos e transformações sentidas como negativas, até então desconhecidos e sucedendo-se a uma velocidade igualmente inédita. Desde esse cenário até o momento inédito, com sérias dificuldades, o urbanismo talvez herde um determinado pessimismo científico a buscar a solução não no conserto, mas sim na fuga, como foi o caso demonstrado pelos urbanistas utópicos: fugir da cidade, construindo novos espaços, pareceria ser a primeira ação concreta de uma ciência recém-nascida. Pessimismo, utopia e otimismo se substituem desde então, sendo a cidade ora passível de solução, ora constituindo o próprio problema da sociedade mundial, ora se constituindo como o mais adequado espaço para o desenvolvimento da história.

Mais recentemente, e essa é uma idéia absolutamente especulativa, o urbanismo, ao assumir a transformação física da cidade, resguarda-se em um longo período de otimismo, ressaltando a massa construída artificialmente pelo homem como o local de criatividade, de geração do conhecimento e de libertação ${ }^{3}$. Impregnado pela imagem da transformação pontual capaz de fazer o urbanismo contemporâneo vivenciar uma forte crença na transformação da cidade. Tal postura pode ser confirmada pela autoconfiança que parece estar presente em muitas intervenções as quais justificariam a imagem de uma atual renascença urbana. Sem dúvida, o cenário ora trazido pelas intervenções em cidades dos Estados Unidos, Europa, seguidas de outras nos demais continentes, opõe-se fortemente às cidades dos anos 60 até meados dos 80. Pessimismos como o revelado pela visão quase pastoral nas propostas urbanas de Frank Lloyd Wright (1932-1959) ou no desencanto de Lewis Munford (1895-1990)4, por exemplo, podem sintetizar esses anos, nos quais cidades cresceram a taxas demográficas elevadas, a crise econômica generalizada exigiu novas fórmulas de gestão urbana e os centros tradicionais (símbolos de uma história local e agregadores de uma comunidade) conheceram a degradação.

Alimentadas pelo pessimismo ou pelo otimismo de uma época, as bases do urbanismo começavam a consolidar-se: não apenas aquelas a justificarem uma intervenção física segundo a concepção do arquiteto ou do engenheiro, mas aquelas que traduziriam a complexa síntese - se isso for possível - das diversas feições da sociedade, em tempo e em espaço determinados.

Mesmo com algumas reincidências (como as cidades ecológicas, autosustentáveis ou ambientalmente corretas dos anos 80 e 90), tal complexidade de fatores urbanos correlacionados em diferentes escalas sinalizava o fracasso de inúmeras tentativas - concretas ou teóricas - de formular-se uma cidade ideal. Como identificar esse ideal, para quem ele serve e em qual momento ele poderia ser visualizado seriam, pois, as perguntas não-formuladas explicitamente. 
(5) Cerdá foi responsável pelo projeto de ampliação da cidade de Barcelona na metade do século 19. Usou o termo urbe como sinônimo de assentamento humano e urbanização como o processo de agir sobre a urbe. Desses termos surge urbanismo. Em seus estudos sobre Barcelona e também Madri, Cerdá discutia temas que variavam desde infra-estruturas até questões de ordem mais territorial e sistema de cidades. Sua obra Teoria geral da urbanização compila seu conhecimento adquirido e relata sua prática.
Fica, assim, evidente que o urbanismo se apresenta como uma ciência voltada a um fenômeno que se complexifica na essência e no entendimento requerido; mais: a abrangência de tal fenômeno não se restringe, e, portanto, não pode ser assim restritamente enfrentado, quando de sua concretização em aglomerados edificados (as cidades). O urbanismo, ou uma ciência do urbano, avança de uma posição marginal em outras ciências, como a sociologia, e mesmo de uma compreensão limitada de seu objeto para, processualmente, constituir uma ciência própria; a um tempo independente e agregadora de diferentes conhecimentos. Nessa ampliação de preocupações, o conceito até então utilizado para o urbanismo, em seu sentido mais restrito, já não parece ser suficiente, ampliando-se para algo maior, algo a planejar não apenas uma ação concreta, mas pontual, para um planejamento maior, de totalidade, tal qual se quer o planejamento urbano e regional.

Finalizando este item, vale lembrar que as idéias apresentadas acima ainda são hipóteses a serem melhor debatidas com outros autores. De qualquer maneira, na ousadia de defender-se essa hipótese, reitera-se o caráter provocativo deste artigo.

\section{A APROXIMAÇÃO DO URBANISMO COM A ARTE E A ARQUITETURA}

É recorrente, na discussão epistemológica do urbanismo, localizar seu surgimento formal, tal qual lembrado por Françoise Choay (1965), em Ildefonso Ildefonso Cerdá5, quando de sua Teoria geral da urbanização, de 1867. De fato: "Con Cerdà aparece el concepto de urbanismo como una visión científica integral de la construcción de las ciudades, sustentada en los métodos de análisis cuantitativos como medios para explicar los hechos sociales y garantizar una propuesta que sea fundamentalmente realizable, alejándose de esta manera de la línea de los utópicos." (ALARCÓN, María Teresa, 2008)

Assim, já nesse momento, com Cerdá, o urbanismo apareceria como uma ciência capaz de elaborar críticas e soluções ao espaço urbano, porém sempre evidenciando uma preocupação com a cidade em termos de espaço construído a ser criado, corrigido ou refeito. Mais tarde, nos anos 30, um arquiteto francês, também conhecido no Brasil, Alfred Agache, apresentaria o urbanismo como:

"Uma ciência, e uma arte e, sobretudo uma filosofia social. Entendese por urbanismo, o conjunto de regras aplicadas ao melhoramento das edificações, do arruamento, da circulação e do descongestionamento das artérias públicas. É a remodelação, a extensão e o embelezamento de uma cidade, levados a efeito, mediante um estudo metódico da geografia humana e da topografia urbana sem descurar as soluções financeiras." (AGACHE, A., 1931, apud CARVALHO SANTOS, José Lazaro de)

Ao se analisar as obras de Ildefonso Cerdá e Alfred Agache, para nos limitarmos a dois nomes conhecidos, preocupados em definir a ciência do urbanismo, tem-se que suas atuações profissionais poderiam, também, ser 
6) Urbanista, opositor das idéias e intervenções de Prestes Maia, idealizador do Plano Regional de São Paulo. Tal oposição, todavia, não diminui a concordância entre ambos - de o zoneamento ser um instrumento fundamental para o planejamento, ordenador mesmo do "caos" (FELDMAN, 2005).

(7) Prefeito duas vezes da cidade de São Paulo, de 1938 a 1945, e de 1961 a 1965. Engenheiro, caracterizou seus mandatos pelas obras implementadas no município. Dessas, vale citar o Plano de Avenidas, com inspiração

haussmaniana. conceituadas como de planejamento urbano e não propriamente de urbanismo. Essa suposição se deve ao fato de, nas idéias desses autores representativos de uma época, ressaltar-se a preocupação com fatos os quais vão além do simples desejo de intervenção, mas avança para uma compreensão mais abrangente da cidade, ou melhor dito, da vida urbana. De fato, Cerdá, ao traçar a forma de ocupação de Barcelona, ressaltando a convivência comunitária, ou Agache ao definir, em alguns de seus trabalhos, uma especialização funcional estanque, preparavam essas cidades para um futuro de forma processual. Por um lado, tal fato aproximava suas realizações profissionais de um planejamento, ou seja, de uma organização futura da cidade. Em um e outro casos, ditavam-se as regras, planejava-se o futuro da cidade, para, ao longo do tempo, essa adquirir a feição desejada. Por outro, as soluções propostas por esses urbanistas ainda estavam distantes das propostas de caráter mais estrutural, as quais considerassem a complexidade de forças sociais e econômicas que, verdadeiramente, formatam as cidades. Todavia, em avaliação mais superficial do trabalho de Cerdá ou de Agache, estes parecem acreditar na construção de uma nova cidade tão-somente pelo desenho do espaço urbano, pelo desenho da manifestação do fenômeno desejado, e não pela lida da dinâmica urbana (embates sociais, políticos, econômicos e culturais em diferentes escalas).

Tal distinção nos lembra, também, a errônea separação do planejar e do agir, fazendo planejamento e urbanismo se apresentarem não apenas como distintos, mas igualmente como opostos. Sarah Fedlman (2005) ilustra essa "discórdia" com a oposição do professor Anhaia Mello 6 ao trabalho de Prestes Maia $^{7}$ na prefeitura da cidade de São Paulo, na qual o primeiro reivindicava o "aparelhamento do setor de urbanismo" para criar planos, e não apenas operações de ordenamento viário.

"Não cremos que o urbanismo municipal tenha deixado de fazer 'planos' por incapacidade, ou má orientação, mas muito simplesmente porque este campo é vago e neles os técnicos estariam desprovidos de base opinativa credenciada de democraticamente invocada ... Estariam eles laborando no ar e perdendo tempo, que aliás têm aproveitado bem, fazendo justamente projetos de voire..." (PRESTES MAIA, 1954, apud FELDMAN, 2005)

Mais uma vez recorrendo-se a Feldman (2005), o domínio de arquitetos e de engenheiros no urbanismo pode ser observado nas palavras de Anhaia Mello a defender a formação especializada do urbanista, ou seja, não como a apropriação por outras formações profissionais. Mello ressalta o papel do arquiteto como "perito na obra de bem construir" e do engenheiro civil, como "entendido na construção de ruas, pontes, pavimentações, transportes". Em ampliação do conceito, agregando ao urbanismo um perfil multidisciplinar, considerava ainda "necessária e imprescindível a colaboração e cooperação do jurista, do legislador, do economista, do sociólogo..." (ANHAIA MELLO, 1928, apud FELDMAN, 2005). "De fato, nos Estados Unidos dos anos de 1920, já havia uma clara distinção entre as atribuições de quem projeto (o arquiteto), quem constrói (o engenheiro), e quem planeja (arquitetos, paisagistas, advogados, engenheiros)." (FELDMAN, 2005)

Agache define urbanismo em um tempo anterior ao de sua própria atuação profissional, na realização de planos de ocupação urbana, a qual desenvolveria 
(8) Exemplos dessa aproximação podem ser encontrados nos trabalhos dos arquitetos chamados internacionais, a emprestarem seus nomes a projetos urbanos de caráter estratégico. Vale ressaltar a figura de Frank Gehry, com seu Museu Guggenheim, integrante de projeto de renovação urbana em Bilbao, Espanha. mais intensamente na década de 1940. Isso talvez explique a incongruência conceitual a respeito de sua ciência. Na realidade, Agache, em sua definição de urbanismo, reproduz a preocupação com a forma e a plástica, ou seja, com uma arquitetura de representação. Sem dúvida, se visto por sua gênese, o urbanismo estará sempre associado à arquitetura e à arte e sempre como uma ciência que observa seu objeto pelo viés desse par. Todavia, a despeito dessa conexão nas origens, e certamente isso qualificaria o futuro do urbanismo, observa-se um vaivêm que mescla proximidade e distanciamento em sua relação com essas mesmas arquitetura e arte. A outra hipótese que se lança neste artigo é a de, ao distanciarmos o urbanismo da arte e da arquitetura, aproximamo-nos do planejamento urbano, este mais preocupado com um intrincado sistema de relações socioeconômicas.

Nos anos 70, pode-se falar em quase rompimento entre urbanismo e arquitetura, ao se buscar soluções tão-somente estruturais para as cidades, aguardando a grande revolução na sociedade para ser possível resolver os problemas urbanos. Para ilustrar esse distanciamento do urbanismo com suas raízes mais pragmáticas, vale lembrar R. Gutman, já em 1961: “Um número crescente de urbanistas profissionais (planners, em inglês) ao invés de se concentrarem na transformação e no controle do meio físico, se preocupam atualmente a modelar as estruturas sociais e culturais da cidade." Do mesmo modo, Manuel Castells, referência obrigatória para se compreender a cidade nos anos 70 e 80, resume a "questão urbana" como um fenômeno que, obrigatoriamente, vai além "da deformação da realidade pelo positivismo" (1983; primeira edição em 1971). Com isso o autor rejeita as idéias de procurar-se entender o fenômeno urbano de forma positivista ou mesmo tecnicista, ignorando formas mais complexas de uma realiade social, econômica e política.

Já no final dos anos 80, ao contrário da década que a havia antecedido, com as iniciativas da renascença urbana em cidades da Europa e Estados Unidos, avançou-se para uma proximidade jamais vista entre urbanismo e arquitetura. Combinando um discurso de requalificação das áreas centrais das cidades, o urbanismo vai, mais uma vez, buscar a aproximação com a arquitetura e com as artes. Com a primeira, tal proximidade ocorre na implementação dos chamados grandes projetos urbanos ${ }^{8}$, quase sempre ícones assinados por arquitetos de renome e pretensamente habilitados para garantir competitividade à cidade que os contêm. Com a arte, o urbanismo se aproxima não apenas por suas expressões visuais concretizadas nos mesmos grandes projetos urbanos, mas também na função desses edifícios, abrigando e fomentando atividades artísticas, culturais e de entretenimento.

\section{MudanÇAS E PERMANÊNCIAS}

A despeito de ampliações no entendimento, pelo urbanismo, de seu próprio objeto, ele não deixa de guardar muitas de suas características originais; fato o qual tem gerado, inclusive, uma das principais críticas ao seu produto. Disso surgem dois receios. O primeiro diz respeito ao alcance do desejo da prancheta do arquiteto - ainda que traduzido em intervenção 
concreta - sobre as relações da sociedade. O segundo é sobre o risco de, ao ampliar as bases de seu entendimento, agregando preocupações socioeconômicas às suas propostas, o urbanismo acreditar poder alterar a sociedade. Se focado na transformação física do espaço, como explicar o uso do conceito urbanismo - e não de planejamento urbano - para traduzir os interesses, por exemplo, do movimento moderno? Sem necessariamente criticar, Françoise Choay (1965) afirma que o urbanismo, tal qual reivindicado por Le Corbusier, é entendido como uma universalidade científica capaz de sintetizar o ponto de vista correto sobre o problema das cidades. De fato, é da fase do urbanismo modernista, desencadeado pelos congressos internacionais de arquitetura moderna/CIAMs e dos quais Le Corbusier é um dos mais proeminentes porta-vozes, que se agudiza o entendimento do urbanismo como uma extensão da atividade profissional do arquiteto e, assim, opõe-se a um entendimento multidisciplinar cada vez mais exigido. Domínio ainda reservado, em sua maior parte, a arquitetos, o urbanismo corre o risco de implementar-se por meio de atitudes concretas capazes de transformar a base física de um determinado espaço urbano, ou de um compartimento, porém desprovidas de visão política e social mais abrangente. Assim, se reservada sua atuação a determinados especialistas, como afirma Françoise Choay (1965), o urbanismo se apresenta "pesado de ambigüidade". Persiste, pois, no urbanismo, sua crença de solução do problema urbano por meio de sua técnica e sua pretensão a propor um modelo de cidade ideal, a partir de cânones hegemônicos para cada uma das épocas que vivencia.

É nos anos 50, no período de reconstrução pós-guerra, na Europa e nos Estados Unidos, afirma Choay (1965), que o urbanismo se submete, mais uma vez, a grandes mudanças. Agora ele recebe a contribuição de diferentes outras perspectivas, garantindo a visão necessariamente mais analítica e mesmo crítica da cidade enquanto espaço de relação das diferentes classes sociais.

Definitivamente, o urbanismo não seria mais um campo de atuação solitária do arquiteto, rechaçando-se, categoricamente, afirmações como a de Le Corbusier, quase de caráter corporativista:

"... o urbanista nada mais é que o arquiteto. O primeiro organiza os espaços arquitetônicos, fixa o lugar e a destinação dos continentes construídos, liga todas as coisas no tempo e no espaço por meio de uma rede de circulações. E o outro, o arquiteto, ainda que interessado numa simples habitação e, nesta habitação numa mera cozinha, também constrói continentes, cria espaços, decide sobre circulações. No plano do ato criativo são um só o arquiteto e o urbanista..." (LE CORBUSIER, 1985, apud SOUZA, 2002)

Conclui-se, portanto, sobre a chamada ambigüidade do urbanismo, sua gênese que valoriza a intervenção física, a permanência dessa prioridade em sua prática e a recorrente mutação em ora se propor a construir uma nova cidade a partir de uma nova sociedade, ora a redefenir a sociedade a partir de suas intervenções. Assim, mesmo guardando as particularidades de sua gênese, sempre vinculado às suas ciências de origem, a arquitetura e a arte tanto se aproximam como se afastam daquilo que parece ser a preocupação multidsciplinar do planejamento urbano. 
A pretensa exclusividade do urbanismo ao profissional da arquitetura, considerando todo o impacto que isso gera no desenvolvimento dessa ciência, explicita a distinção entre ele e o planejamento urbano.

Se urbanismo e planejamento urbano se preocupam com os fenômenos que moldam a cidade, ampliando-a, evidentemente, para espaços regionais e macrorregionais, eles diferem com mais evidência pela forma como atuam. Enquanto o urbanismo permanece menos multidisciplinar e historicamente preocupado com o desenho que a cidade pode assumir, pela ocupação e uso enganosamente homogêneo dos agentes urbanos, o planejamento urbano se preocupa com os conflitos os quais esse uso e essa ocupação, obrigatoriamente, geram sobre o espaço da cidade. Desnecessário dizer que, enquanto o primeiro sobrevive em seus objetivos e responsabilidades de modo mais monodisciplinar, o segundo, obrigatoriamente, busca o concerto difícil de inúmeras outras ciências. A diferença entre um e outro não significa que 0 urbanismo possa existir sem planejamento, sem contar com um momento anterior no qual se planeja e um momento no qual se executa o planejado. De fato, não parece plausível vislumbrar uma obra urbana, um projeto de intervenção, sem antes planejá-lo; do mesmo modo, não se planeja algo que não se acredita poder acontecer de fato.

Se o início do urbanismo poderia ser datado na metade do século 19, o planejamento urbano, por sua vez, parece surgir como um desejo mais explícito de regulação do estado no período pós-1945 e com maior vigor nos países socialistas e comunistas, justamente onde seria maior a importância do estado na sociedade e na economia. Todavia, na discussão sobre as diferenças entre um e outro, vale a lembrança de as cidades serem construídas, destruídas e atualizadas desde períodos tão remotos quanto o próprio fenômeno da urbanização. Do mesmo modo, o pensar anterior ao agir, ainda que não formulado com clareza científica, é, evidentemente, encontrado em tempos também pretéritos. Tal constatação coloca em dúvida, portanto, a separação entre uma e outra ciência e seu surgimento em determinado momento preciso da história. Isso permite, talvez, o uso indistinto desses dois termos e, o mais importante, implica na impossibilidade de sintetizá-los conceitualmente com clareza. Além da diferença entre os tempos de surgimento de um e de outro, acreditando que conjunturas diferentes criaram demandas diferentes, deve-se ressaltar a distinção de cada um em encarar o fenômeno urbano.

Outra maneira de ver a diferença entre urbanismo e planejamento urbano é considerar o segundo como um conceito ampliado, uma ciência mais ampla. Esse se ocuparia, pois, de atividades relacionadas à pesquisa, planos setoriais diversos, regulação e controle do uso do solo e atividades relacionadas, como a garantia do atendimento a serviços (educação, saúde e segurança) e infraestruturas básicas (redes de água, esgoto, pavimentação, transporte).

De tal atuação ampla, o planejamento urbano conviveria com outras ciências, confundindo-se mesmo, em alguns momentos, com a sociologia, geografia, economia e ciências políticas. Assim, confirma-se a idéia de 0 planejamento urbano mostrar-se como uma ciência de caráter eminentemente multidisciplinar e preocupada com a forma societária desenvolvida em seu espaço de interesse, a cidade. No outro extremo, o urbanismo estaria preocupado com partes de uma cidade ou, como é sempre lembrado, na 
(9) Esses princípios podem ser assim sintetizados: caminhabilidade, conectividade, integração de funções urbanas, qualidade da arquitetura e do desenho urbano, integração comunitária, densidade adequada, transporte inteligente, sustentabilidade e qualidade de vida (www.newurbanism.org, 2007).

(10) Para conhecer a crítica ao discurso e à obra de Le Corbusier, aconselhamos a leitura da obra Cidades do amanhã, de Peter Hall. proposição de cidades novas, em uma postura utópica ao ver uma nova sociedade sendo criada a partir de um novo desenho do espaço a ser ocupado.

Exemplificando parcialmente essas idéias, pode-se tomar o caso do chamado new urbanism (movimento surgido no início dos anos 80, nos Estados Unidos), sempre entendido como um urban design movement, ou seja, demonstrando uma preocupação primordial com o elemento construído. Os princípios desse movimento ${ }^{9}$, aqui entendido como uma proposta para partes de uma cidade, de fato, alguns empreendimentos comerciais, constituem um desenho específico para uma determinada ocupação urbana do espaço. Com isso, distingue-se urban design (aqui entendido como urbanismo) de urban planning (mais próximo de nosso planejamento urbano).

\section{PLAYING GOD}

Vista segundo uma perspectiva racionalista e positivista, a cidade é um sistema passível de ser ordenado, corrigido e mantido da forma como fora idealizado. A partir dessa premissa dada ao urbanismo, seu profissional se propõe a formular projetos (idéias representadas graficamente e não apenas em palavras) que sintetizem um desejo de cidade ideal. Façamos um projeto, respeitemos esse projeto e, assim, a cidade ideal se fará: essa parece ser, pois, a máxima racionalista e outorgada ao profissional urbanista. O arquiteto, acostumado a uma outra máxima, a de ser possível brincar de Deus, pretensa e facilmente aceita a arriscada outorga.

Fundamentado, assim, em idéias capazes de transformarem-se em intervenções concretas, o urbanismo se submeteria a críticas por se propor, de forma simplista, a corrigir o errado e evitar o mal. Constituindo o que Françoise Choay (1965) chamaria de urbanismo progressista e sempre defendido por Le Corbusier, na idéia de um universalismo do urbanismo modernista ${ }^{10}$, este seria criticado por sua presunção em alterar aspectos sociais, econômicos e culturais.

Apesar das críticas e mesmo da quase hegemônica desconfiança da parte da academia em relação ao urbanismo modernista, ainda hoje persistem, entre nós, a prática da busca de uma cidade funcional, do modelo ideal de cidade, da intervenção física como fonte transformadora principal da cidade.

Se o conceito de urbanismo há muito se confirma como o de uma ciência crítica à sociedade sobre a qual atua (ora propondo novas cidades, ora reformulando partes das existentes), suas ferramentas se limitam tão-somente a alterar o concreto. Mais importante que seu criador, o urbanista é seu objeto criado, a nova cidade; esta sim capaz de tudo mudar. Ao se criar o objeto, delega-se ao mesmo a tarefa de mudar a sociedade. O fracasso de inúmeras tentativas urbanísticas, diferentes no desenho da cidade proposta, mas similares na indiferença em relação à permanência de antigas relações socioeconômicas, confirmam essa idéia.

De um lado, o urbanismo, adotado como instrumento da ação estratégica e de resultados visíveis em curto espaço de tempo; de outro, o planejamento urbano se prestando àqueles que acreditam na transformação estrutural da sociedade. Na eqüidistância dessas posturas profissionais, um fértil campo de 
(11) Exemplifica-se esse comentário por meio da crença exacerbada, na década de 2000, no Brasil, de os planos diretores serem suficientes para se construir uma política urbana: discutem-se os problemas da cidade, dãose oportunidades para o debate democrático sobre "a cidade que se deseja", mas se adia as transformações necessárias e há muito requeridas.

(12) Refere-se, aqui, à escola que se propõe a discutir a cidade de um ponto de vista social e antropológico. Referência obrigatória nos estudos da cidade durante a primeira metade do século 20, teve como principais representantes Robert E. Park e Ernest Burgess. atuação abandonado. Todavia, a conjuntura atual de opção neoliberal não contribui para essa conjunção. Se o papel do Estado é reduzido e se o interesse do capital é valorizado, o urbanismo, com seu perfil mais monodisciplinar, é valorizado por crer que, pragmaticamente, pode corrigir erros e construir uma cidade melhor e, idealmente, mais competitiva.

Sem aqui poder se servir de uma pesquisa sobre o assunto, 0 conhecimento empírico pode indicar que, nas universidades brasileiras de arquitetura e urbanismo, ainda influenciadas por um período de maior relevância do Estado, tem-se, sistematicamente, abandonado o estudo da obra, da infra-estrutura, do transporte e mesmo da habitação popular para priorizar o planejamento em seu sentido mais estrito, ou seja, o da lei e o do desejo expresso em palavras ${ }^{11}$. Não se faz, aqui, nenhum juízo de valor. Arrisca-se dizer que, certo ou errado, valoriza-se o ensino da lei e do processo de planejamento em detrimento da prática da intervenção, seja ela feita pelo capital privado, seja pelo Estado, igualmente com capacidade empreendedora. Do mesmo modo, para o contexto norte-americano, Susan S. Fainstein (2005), ao detectar essa separação entre o pensar a cidade - neste artigo, uma ação mais vinculada ao conceito de planejamento urbano - e o intervir nesse espaço, atividade vinculada ao conceito de urbanismo, conclui pela separação entre o aprender a planejar, o de elaborar diagnósticos e o de intervir:

"Programs in city and regional planning typically have one set of courses devoted to the process of planning (planning theory, planning methods), while another group treats the context (structure of cities and regions, urban history) and the object of planning (e. g., redevelopment policy, environmental policy) with little reference to theories of the planning process."

O alerta trazido por Susan S. Fainstein (2005) em relação à baixa conectividade entre o estudar um fenômeno e o intervir sobre esse mesmo fenômeno permite-nos tomar a liberdade de concluir pelo distanciamento contemporâneo entre planejamento urbano e urbanismo.

"'Why has planning theory ceased to be urban?' The impetus for the development of planning lay in a critique of the industrial city and a desire to re-create cities according to enlightened design principles. Whether the focus was on greenfield sites, as in Ebenezer Howard's garden city model, or on redeveloping the existing city, as in Haussmann's Paris and Burnham's City Beautiful, planning devoted itself to producing the desired object. It did so, however, without reflection on the process by which the ideal city was formulated."

Aquilo que antes era buscado como um avanço no entendimento do urbanismo, valorizando sua ampliação temática e profissional, hoje, segundo o entendimento deste autor, parece dar sinais de fragilidade novamente, mas no sentido contrário. Tal mudança de postura profissional, de compreensão científica e mesmo de posicionamento ideológico, a qual o presente artigo arrisca sobrepor a uma eventual transformação do urbanismo em planejamento urbano, pode ser rastreada na sintética afirmação de Jean Louis Saibib (apud FAINSTEIN, 2005). Saibib, de fato, localiza, na Escola de Chicago' ${ }^{12}$, as raízes de pensar-se a questão urbana "from a primarily design profession to a social science". 
A antiga e criticada concepção meramente reificada do urbanismo hoje arriscaria desaparecer, aproximando-o assim, mais uma vez, do planejamento urbano. Todavia, ao se observar as críticas de diversos autores contra um urbanismo de detalhes, pequenos consertos, do magnificente, dos pedaços da cidade, a ação monodisciplinar parece estar fortalecida: "Now we are left with a world without urbanism, only architecture, ever more architecture." (KOOLHASS, 1995)

\section{O DESENHO URBANO}

Apesar de este artigo já caminhar para sua conclusão - tarefa que julgo a mais difícil -, vale ainda anunciar uma discussão sobre mais um termo que guarda forte relação conceitual e profissional com a arquitetura, o urbanismo e também com o planejamento urbano: o desenho urbano. Para tanto, é necessário servir-se da discussão trazida por Vicente del Rio (1990), para quem o desenho urbano pode ser entendido como área específica de atuação do urbanismo. Seria, então, o desenho urbano o detalhamento de um projeto maior de intervenção, tais quais os projetos complementares ao projeto de arquitetura. Estaríamos aqui, pois, na menor escala possível do planejamento urbano, indo além da intervenção propriamente dita, mas avançando para o detalhe. Tal detalhamento, em uma primeira análise, erroneamente nos aproxima da preocupação embelezadora já anteriormente praticada pelo urbanismo em suas origens mais remotas no século 19. Todavia, é importante notar que o desenho urbano, hoje, é fruto da técnica, da ergonometria, da tecnologia, da utilização por veículos e do complexo uso intenso em um espaço urbano, revelando uma preocupação muito mais com a função que com a forma.

Entretanto, a seqüência de planejamento urbano, urbanismo e desenho urbano, muitas vezes, parece corresponder a uma hierarquia de escalas. 0 planejamento seria a única escala capaz de preocupar-se com o contexto regional de uma cidade ou dos diferentes grupos componentes de sua sociedade; o urbanismo teria como escala aquela concretizada pelo espaço urbanizado e/ou a urbanizar, e o desenho urbano preocupado com o detalhe da intervenção.

Consciente da complexidade desse tema, este artigo não pode, porém, deixar de identificar uma outra hierarquia entre esses três conceitos. Mantém-se o desenho urbano como um detalhe projetual da intervenção; contudo, confunde-se a hierarquia entre urbanismo e planejamento urbano. Ermínia Maricato (2000), ao alertar para o fato de a subserviência de muitas intervenções no espaço urbano reforçarem o interesse de uma hegemonia política e econômica, afirma: "... o urbanismo brasileiro (entendido como planejamento e regulação urbanística) não tem comprometimento com a realidade concreta, mas com uma ordem que diz respeito a uma parte da cidade apenas... ." A preocupação da autora aqui é a de reiterar a importância de pensar-se ações para o todo de uma cidade e não para suas partes consideradas legais. 0 aprofundamento dessa discussão poderia confirmar se essa citação apresenta um conceito diferente de urbanismo daquele aqui apresentado, entendido como planejamento e regulação e não, necessariamente, como uma ação pró-ativa de 
intervenção no espaço da cidade. Tal citação pode também, simplesmente, confirmar o uso indistinto dos conceitos de urbanismo e de planejamento urbano.

Quando Villaça (1999) revê a história daquilo que ele chama de urbanismo, mais uma vez o conceito parece ser abrangente, seja pelas determinações históricas, seja pela própria síntese conceitual adotada. Para esse autor, o urbanismo do século 19 até os anos 30 caracteriza-se por planos de embelezamento, de melhoramentos, com objetivos higiênicos ou sanitários; desses anos 30 até os anos 90 do século 20, a cidade brasileira se planeja para o enfrentamento de problemas diversos, sobretudo aqueles decorrentes de um crescimento acelerado; dos anos 90 em diante a ação seria marcada por um período pós-reforma urbana. Se, em todos esses períodos, o autor citado não identifica uma proposta mais estrutural de mudança da cidade, o urbanismo do período por ele analisado corresponde ao conceito que se sugere adotar neste artigo.

I 82 官

\section{Algumas COnclusões}

Se, ao longo da história, o chamado urbanismo ou planejamento urbano contarem com diferentes formas de implementá-lo e nomeá-lo, a correta conceituação dos termos aqui discutidos só seria possível se concebida a partir de uma definição do momento histórico. Nessa discussão epistemológica, mudam os conceitos, confundindo-se com o de outras ciências, ao mesmo tempo em que mudam as formas de buscar-se um determinado modelo de cidade. Em algum momento, sobretudo no urbanismo moderno, buscou-se a cidade ideal por meio de regulações e separações de funções; em outro momento valorizou-se a simples regulação do uso do solo; em outro momento, ainda, o urbanismo buscou a cidade sustentável, valorizando o estudo, a proteção do ambiente natural; por último, pode ter também buscado a cidade democrática que atenda aos interesses de todos ou minimamente da maioria, valorizando a participação comunitária.

"A atividade prática do urbanista tem hoje características que não tinha no passado... Nas últimas décadas do século XX, o campo de práticas urbanísticas inesperadamente se dilatou e abriu... na maioria das vezes, o aspecto do grupo local ou de interesse, que apresenta as próprias demandas em forma de respostas fisicamente determinadas: alargar uma rua ao invés de eliminar o congestionamento de trânsito, criar estacionamentos subterrâneos naquela praça, em vez de garantir um acesso mais fácil às áreas comerciais... O urbanista, mais que quaisquer outros estudiosos e projetistas, para engendrar uma concreta modificação a cidade e do território, deve obter o consenso de uma multiplicidade de sujeitos individuais ou coletivos..." (SECCHI, 2005)

$\mathrm{Na}$ mudança de paradigmas, mudaram-se as ferramentas com as quais 0 urbanismo trabalha, ora se aproximando da intervenção ou mesmo modelagem de um espaço físico, ora se aproximando da construção de uma cidade futura por meio, tão-somente, de uma explicitação visual de um desejo urbano em 
desenho ou em lei. Nesse vaivém, urbanismo e planejamento urbano estariam às vezes mais próximos, às vezes mais distantes.

Este artigo buscou resgatar alguma discussão sobre o conceito de urbanismo e de planejamento urbano. Em nenhum momento considerou correto arriscar uma nova construção conceitual ou mesmo sintetizar o que já fora previamente desenvolvido por outros autores.

Em algum momento, urbanismo pareceu resultar de uma ciência maior o planejamento urbano. Em outros, tem-se a certeza que o correto seria entendê-lo de forma reversa. Assim, o planejamento urbano estaria fazendo parte de uma ciência maior denominada urbanismo. Em alguns outros momentos, ainda, sugere-se a utilização indistinta entre urbanismo e planejamento urbano.

Fica claro, no entanto, tal qual explicitado por Bernardo Secchi (2005), quando este nos fala do "fim do autor", que nos incrementa a complexidade profissional do urbanismo/planejamento urbano, dirigindo-se para um entendimento, obrigatoriamente, multidisciplinar e disposto a submeter-se ao acordado comunitariamente, conforme realidades socioeconômicas e políticas.

Poderíamos, exageradamente, assumir urbanismo como uma ciência cujo objetivo é ordenar os elementos naturais, construídos e societários, no espaço ocupado ou a ser ocupado por um determinado assentamento humano. Tal conceito poderia, ainda, ser ampliado para o tratamento desse conjunto de elementos com seu espaço regional, com a rede nacional e internacional de cidades. Na prática, esse mesmo urbanismo pode ser entendido como uma ciência que se utiliza, prioritariamente, do zoneamento e de intervenções físicas para sua concretização como prática. Ora o conceito é amplo e pretensioso, ora a prática é reducionista.

\section{BiBLIOGRAFIA}

ALARCÓN, María Teresa. El Plan Cerdá para Barcelona y el urbanismo argentino del siglo XIX. Disponível em: <http://www.arq.unne.edu.ar/institucional/publicaciones/areadigital/area2/ alarconplancerda.htm>. Acesso em: ago. 2008.

AGACHE, Alfred. Cidade do Rio de Janeiro, remodelação, extensão e embelezamento (Plano Agache). Rio de Janeiro: Foye Brésilien, 1930.

CARVALHO SANTOS, José Lázaro de. Reflexões por um conceito contemporâneo de urbanismo. Disponível em: <http://www.sburbanismo.vilabol.uol.com.br> Acesso em: nov. 2007.

CASTELLS, Manuel. A questão urbana. São Paulo: Paz e Terra, 1983.

CHOAY, Françoise. O urbanismo, utopias e realidade, uma antologia: São Paulo, Perspectiva: 1965. DEL RIO, Vicente. Introdução ao desenho urbano no processo de planejamento. São Paulo: Pini, 1990.

DIAS, Edson dos. Resgatando o movimento modernista urbano: A expressão de uma conjuntura histórica que marcou as cidades do século XX. Revista Geo Notas, Maringá: Departamento de Geografia, Universidade Estadual de Maringá, v. 4, n. 4, 2000.

FAINSTEIN, Susan S. Planning theory and the city. Disponivel em < http://www.gsd.harvard.edu/ people/faculty/fainstein/text/Planning\%20Theory\%20and\%20the\%20City\%20final.pdf >. Acesso em: jan. 2008.

FELDMAN, Sarah. Planejamento e zoneamento. São Paulo: 1947-1972. São Paulo: Edusp/Fapesp, 2005. 
KOOLHAAS, Rem. What ever happened to urbanism? In: KOOLHAAS, Rem; MAU, Bruce. Small, medium, large, extra large. Nova York: Monacelli Press, 1995.

LE CORBUSIER. Os três estabelecimentos humanos. São Paulo: Perspectiva, 1981.

Urbanismo. São Paulo: Martins Fontes, 1992.

LEME, Maria Cristina da Silva (Org.). Urbanismo no Brasil: 1895-1965. São Paulo: Studio Nobel/ FAUUSP/Fupam, 1999.

MARICATO, Ermínia. As idéias fora do lugar e o lugar fora das idéias. Planejamento urbano no Brasil. In: ARANTES, Otília et al. A cidade do pensamento único. Petrópolis: Vozes, 2000.

MUNFORD, Lewis. A cidade na história: Suas origens, suas transformações, suas perspectivas. São Paulo: Martins Fontes, 1965.

NEW URBANISM. Site oficial: <http://www.newurbanism.org>. Acesso em: dez. 2006.

SECCHI, Bernardo. Primeira lição de urbanismo. São Paulo: Perspectiva, 2005.

SOUZA, Marcelo Lopes de. Mudar a cidade: Uma introdução crítica ao planejamento e à gestão urbanos. Rio de Janeiro: Bertrand Brasil, 2002.

VILLAÇA, Flávio. Uma contribuição para a história do planejamento urbano no Brasil. In: DEÁK, Csaba; SCHIFFER, Sueli Ramos (Orgs.). O processo de Urbanização no Brasil. São Paulo: Edusp/ Fupam, 1999.

I 84

is

\section{Nota do Editor}

Data de submissão: agosto 2008

Aprovação: janeiro 2009

\section{Clóvis Ultramari}

Graduado em Arquitetura e Urbanismo pela Universidade do Paraná e doutorado em Meio Ambiente e Desenvolvimento Urbano pela mesma universidade. Atualmente é professor titular da Pontifícia Universidade Católica do Paraná e professor-pesquisador do mestrado em Gestão Urbana na mesma universidade. Pesquisador do Instituto Paranaense de Desenvolvimento Econômico e Social - IPARDES.

Pontifícia Universidade Católica do Paraná Rua Imaculada Conceição, s/n. Prado Velho 80215-901 - Curitiba, PR

(41) 3271-1447

ultramari@yahoo.com 